\title{
Intake dynamics of goats and llamas feeding on garrigue grazing lands
}

\author{
B Dumont ${ }^{1}, \mathrm{M}$ Meuret ${ }^{2}$ \\ 1 ENSA-INRA, chaire de Zootechnie, 9 place Viala, 34060 Montpellier Cedex 1; \\ 2 INRA-SAD, unité d'Ecodéveloppement, domaine Saint-Paul, 84143 Montfavet Cedex, France
}

\begin{abstract}
A comparison was made of intake dynamics in goats and llamas grazing continuously year round on garrigue rangeland paddocks (Languedoc, France). A heavy grazing impact was desired in order to reduce shrub vegetation. The grazing behaviour of 1 individual of each species was observed continuously, during the 17-h daylight period, using the bite-count technique.
\end{abstract}

The 2 flocks (21 goats and 11 llamas) were allocated in June 1991 to 2 different 0.5-ha paddocks, where Quercus coccifera, Rosmarinus officinalis and Brachypodium ramosum were dominant. Stocking densities were close to $1600 \mathrm{~kg}$ liveweight $(\mathrm{LW}) / \mathrm{ha} \cdot \mathrm{d}$. The llamas were fed a daily supplement of $250 \mathrm{~g}$ barley and minerals. The goats were supplemented with minerals only. Data-recording days (D3, D17, D31) were staggered in time from an almost intact vegetation to a situation where mostly unpalatable plants remained abundant. The llama under observation, a 3-yr old non-castrated male weighing $111 \mathrm{~kg} \mathrm{LW}$, had lived on the garrigue for 15 months. The goat, a dry 6-yr-old female, weighed $52 \mathrm{~kg}$ and had always lived on the garrigue. To estimate intake with greater accuracy, bites given on each species were divided into classes of distinct structural composition and mass (Meuret, 1989). Fifty-two types of bites were defined for the 15 species consumed, the 4 main species each being divided into 8 different bites. A meal was defined as an intake period lasting at least $20 \mathrm{~min}$ with interruptions of no longer than $15 \mathrm{~min}$. To assess within-meal intake dynamics, the recordings were divided into 5-min periods.
Daily dry matter (DM) intake at pasture during the daytime (gDM/kg LW0.75) was $30-65 \%$ higher in the goat: 76 vs 53 (D3); 41 vs 32 (D17); 42 vs 26 (D31). The goat also consumed a far higher proportion (\%DM) of woody material: 99 vs 22 (D3); 98 vs 44 (D17); 83 vs 66 (D31). Intake estimates on D3 were consistent with those found in the literature for intake/24 $\mathrm{h}$ (Dumont, 1991). The number of daily meals (4-8) was similar in both species. The shape of meal curves generally did not take the form of decreasing exponentials as observed in penned animals. Initial intake rates (5-35 $\mathrm{min})$ remain between $0.02-0.20 \mathrm{~g} \mathrm{DM} / \mathrm{min} \cdot \mathrm{kg} \mathrm{LW} 0.75$. These were under those recorded with herded or penned dry and lactating goats grazing on various pastures $(0.20-0.70 \mathrm{~g})$. It appears that the vegetation structure may hinder intake rates $>0.30 \mathrm{~g} \mathrm{DM} / \mathrm{min} \cdot \mathrm{kg} \mathrm{LW}$ L.75, whereas with other types of foliage these may be twice as high (Meuret, 1989). These limited rates were not compensated by increasing the time spent grazing (llama: 542 min \pm 61 ; goat: 413 min \pm 54 ) during the observation period.

Dumont B (1991) DEA, Univ Tours et Rennes I, $37 p$

Meuret $M$ (1989) Thèse Sci Agron, Gembloux, $246 p$ 